\title{
Providing Unique Support for Health Study Among Young Black and Latinx Men Who Have Sex With Men and Young Black and Latinx Transgender Women Living in 3 Urban Cities in the United States: Protocol for a Coach-Based Mobile-Enhanced Randomized Control Trial
}

Renata Arrington-Sanders ${ }^{1}$, MD, MPH, ScM; Kimberly Hailey-Fair ${ }^{1}$, MPH, CPH; Andrea Wirtz ${ }^{2}$, PhD; Travis Cos $^{3}$, $\mathrm{PhD}$; Noya Galai ${ }^{2,4}, \mathrm{PhD}$; Durryle Brooks ${ }^{2}, \mathrm{PhD}$; Marne Castillo ${ }^{5}, \mathrm{PhD}$; Nadia Dowshen ${ }^{6}, \mathrm{MD}$, MSHP; Constance Trexler $^{7}$, RN, CPN, BSN, MSHS; Lawrence J D’Angelo ${ }^{7}$, MD, MPH; Jennafer Kwait ${ }^{1}$, PhD, MHS; Chris Beyrer ${ }^{2}$, MD; Anthony Morgan ${ }^{1}$, AAS; David Celentano ${ }^{2}$, SCD; PUSH Study ${ }^{1,2,5,7}$

\footnotetext{
${ }^{1}$ Division of Adolescent and Young Adult Medicine, Johns Hopkins School of Medicine, Baltimore, MD, United States

${ }^{2}$ Department of Epidemiology, Johns Hopkins Bloomberg School of Public Health, Baltimore, MD, United States

${ }^{3}$ Public Health Management Corporation Research \& Evaluation Group, Philadelphia, PA, United States

${ }^{4}$ Department of Statistics, University of Haifa, Mt Carmel, Israel

${ }^{5}$ The Adolescent Initiative, Children's Hospital of Philadelphia, Philadelphia, MD, United States

${ }^{6}$ Craig Dalsimer Division of Adolescent Medicine, Children's Hospital of Philadelphia, Philadelphia, MD, United States

${ }^{7}$ Adolescent Clinical Research Burgess Clinic, Children's National Medical Center, Washington, DC, United States
}

\section{Corresponding Author:}

Renata Arrington-Sanders, MD, MPH, ScM

Division of Adolescent and Young Adult Medicine

Johns Hopkins School of Medicine

200 North Wolfe Street

Baltimore, MD

United States

Phone: 14105028166

Email: rarring3@jhmi.edu

\begin{abstract}
Background: The US National HIV/AIDS Strategy 2020 calls for increasing access to care, improving outcomes of people living with HIV, and targeting biomedical prevention efforts, including access to pre-exposure prophylaxis (PrEP) in communities where HIV is most heavily concentrated. The cities of Baltimore, Maryland (MD); Washington, DC; and Philadelphia, Pennsylvania (PA) are disproportionately burdened by high rates of new cases of HIV infection, with high prevalence among young Black and Latinx men who have sex with men (YBLMSM) and young Black and Latinx transgender women (YBLTW) aged 15-24 years.

Objective: This study aims (1) to identify and recruit YBLMSM and YBLTW who are at risk or living with HIV in Baltimore, MD; Philadelphia, PA; and Washington, DC, using respondent-driven sampling (RDS) with targeted seed selection, and (2) to assess the efficacy of a coach-based mobile-enhanced intervention (MEI) compared with standard of care (SOC) to increase successful engagement and retention into HIV, PrEP, and substance use treatment care across the HIV care and prevention continua in 3 Mid-Atlantic cities. This paper describes the protocol and progress as of October 20, 2019.

Methods: This study uses a multiphase mixed methods design. The first phase is a formative, qualitative research with focus group discussions and key informant interviews. The second phase consists of evaluating the ability of RDS with targeted seed selection. The third phase includes 2 embedded randomized controlled trials (RCTs), where participants complete a baseline sociobehavioral survey, rapid HIV testing, and eligible youth enroll in parallel status-dependent RCTs that randomize the participant to 1 of 2 study arms: MEI with coach or SOC. Participants are asked to complete a web-based survey and provide biologic specimens-HIV-1 RNA (viral load) or HIV-1 antibody test and urine drug screen—at baseline and at 3, 6, and 12 months, and an exit interview at 18 months.
\end{abstract}


Results: A formative qualitative research was conducted in February 2017 and May 2018, and this led to further refinement of recruitment and study methods. Aim 1 recruitment began in September 2017 with subsequent enrollment into the RCTs. Recruitment is ongoing with 520 participants screened and $402(77.3 \%)$ enrolled in aim 1 by October 2020. Of these, 159 are enrolled in the 2 randomized trials: 36 (22.6\%) HIV-positive not virally suppressed (aim 2) and 123 (77.4\%) high-risk HIV-negative (aim 3).

Conclusions: This study has the potential to significantly impact the medical and substance use services provided to YBLMSM and YBLTW in the United States by providing rigorous scientific evidence outlining approaches and strategies that improve the uptake and engagement of YBLMSM and YBLTW in the HIV treatment and prevention continuum.

Trial Registration: ClinicalTrials.gov NCT03194477; https://clinicaltrials.gov/ct2/show/NCT03194477

International Registered Report Identifier (IRRID)： DERR1-10.2196/17269

(JMIR Res Protoc 2020;9(9):e17269) doi: 10.2196/17269

\section{KEYWORDS}

African-American; Latinx; men and transgender; HIV; youth; mobile phone

\section{Introduction}

\section{Background}

The US National HIV/AIDS Strategy 2020 [1] calls for (1) increasing access to care and improving outcomes of people living with HIV and (2) targeting biomedical prevention efforts, including access to pre-exposure prophylaxis (PrEP) in communities where HIV is most heavily concentrated. The cities of Baltimore, Maryland; Washington, DC; and Philadelphia, Pennsylvania, are disproportionately burdened by high rates of new cases of HIV infection, with highly elevated rates among young Black and Latinx men who have sex with men (YBLMSM) and young Black and Latinx transgender women (YBLTW) aged 15-24 years [2-5]. This underscores the need for increased identification, linkage, and initiation in HIV treatment and preventive care for these populations.

Strategies to change the trajectory of the epidemic for those most affected now focus on status-based cascade approaches that seek to systematically connect individuals at different stages within the HIV continuum to different stages of prevention and treatment to reduce their likelihood of acquiring HIV, and for those with HIV, achieving viral suppression [6-8]. The cascade approach seeks to identify one's HIV infection status and immediately engage the individual in HIV prevention, typically using PrEP, or in HIV care. Although earlier engagement in the HIV care cascade can improve the overall outcomes, YBLMSM and YBLTW disproportionately fall out of the treatment cascade at an early stage [9]. Both YBLMSM and YBLTW are less likely than White young men who have sex with men (MSM) or their White cisgender peers to receive, adhere, and obtain HIV viral suppression with antiretroviral therapy (ART) [10,11]. Moreover, YBLMSM and YBLTW at risk for HIV have had disproportionately lower rates of PrEP uptake and adherence $[3,12,13]$.

High rates of substance use [14] in YBLMSM and YBLTW have been identified as key factors that influence treatment and prevention engagement [15-17]. YBLMSM and YBLTW with substance use disorders (SUDs) and risky substance use may be less likely to perceive a need for treatment and more likely to experience barriers to engaging in care $[18,19]$. Findings in other research indicate that behavioral interventions should assess substance use to inform clinical guidance in education and medical consultation for young MSM [20]. Related anxiety and other mental health diagnoses, which are often associated with substance use, may also be relevant to informing an intervention to reduce risk behavior [21]. As such, substance use interventions may increase the effectiveness of HIV treatment and prevention programs [22].

Communities of color and low-income communities often experience limited access to HIV care, substance treatment, and lesbian, gay, bisexual, transgender, queer (LGBTQ) services [19,23-26]. Multiple barriers have been identified, including barriers related to race, sexual identity, gender identity, and intersectional discrimination or stigma experienced from existing within multiple marginalized identities [27-30]. Concerns about confidentiality and mistrust have also been identified as barriers for youth [31]. Youth-based interventions that are accessible and simultaneously address HIV care, prevention, and substance use treatment behaviors are needed, yet few exist [14].

One strategy that has shown promise in identifying hard-to-reach MSM and transgender women (TW) at risk of HIV and providing them with the opportunity to receive PrEP, early ART, and substance use is a peer-driven recruitment [32]. Peer-driven recruitment has been identified as an effective strategy to reach MSM, including young Black MSM, and TW at high risk of HIV in the United States and Thailand $[33,34]$. In both studies, peer recruitment resulted in earlier access to HIV and prevention services, including PrEP and early ART [32,34]. Respondent-driven sampling (RDS) is a peer recruitment strategy that has been used to identify and engage hard-to-reach HIV-infected but untreated Black MSM in HIV care [32,35,36]. Typically, RDS involves a chain-referral procedure in which well-networked individuals (seeds) are asked to invite a number of peers from a specified population to be screened for a study. The seeds are often given a certain number of enrollment slips or coupons to provide to their peers. YBLMSM and YBLTW social networks are likely to overlap. However, limited studies have sought to use RDS to recruit these overlapping populations. Tailored strategies for youth, such as incorporating RDS seeds from social networks, may improve the identification and recruitment of HIV-infected and high-risk HIV-uninfected YBLMSM and YBLTW and identify individuals with comorbid factors, including substance use, that may impact engagement and retention in care and prevention [37]. 
With $94 \%$ of Black teens and $99 \%$ of lesbian, gay, bisexual, and transgender young adults owning or having access to a smartphone [38], mobile-based interventions have the potential to engage youth in HIV prevention and the treatment cascade [39]. The benefits of mobile apps to engage gay and bisexual men have been documented by other researchers [40-42]. However, few have tried to simultaneously address both the HIV prevention and treatment cascade and substance use behaviors that may coexist among YBLMSM and YBLTW. Further, engagement in prevention and treatment has been a challenge even for prior studies that have effectively demonstrated short-term changes in condom use behavior [43]. Peer support (or coaching) with a mobile app has the potential to improve engagement through interactive motivational feedback around HIV and substance use risk. Such approaches have the capacity to screen adolescents for HIV risk and provide brief substance use interventions that are a flexible, low-intensity strategy that empowers youth and connects them to earlier access to HIV treatment, prevention services, and reduction of specific risks identified. This may be prudent given the prior studies that have demonstrated that community-based mentoring and peer support effectively build resilience and address barriers to care, including stigma and homophobia in YBLMSM and YBLTW [44-46]. To date, however, few studies have examined such approaches among YBLMSM and YBLTW living in the United States.

\section{Objectives}

The goal of this paper is to describe a study protocol to (1) identify and recruit YBLMSM and YBLTW who are at risk or living with HIV in Baltimore, MD; Philadelphia, PA; and Washington, DC, and (2) to assess the efficacy of a coach-based mobile-enhanced intervention (MEI) compared with standard of care (SOC) to increase successful engagement and retention in HIV care, prevention, and substance use treatment for YBLMSM and YBLTW living in the 3 Mid-Atlantic cities. Ultimately, we are interested in using the HIV care and prevention continuum $[2,47]$ to evaluate strategies to identify and engage YBLMSM and YBLTW who are at risk or living with HIV, while simultaneously addressing substance use comorbidity [48]. The manuscript focuses on the development and formative work of this study and a summary of the protocol.

The research protocol described here is a collaboration between the Johns Hopkins Schools of Medicine (Harriet Lane Clinic) and Bloomberg School of Public Health, the Public Health Management Corporation, and 3 collaborating sites: Children's Hospital of Philadelphia (CHOP), Children's National Hospital, and Whitman-Walker Health.

\section{Methods}

\section{Study Design}

This study uses a multiphase mixed methods design [49]. The first phase is an exploratory, incorporating formative, qualitative research with key informant interviews (KIIs) and focus group discussions (FGDs). These KIIs and FGDs are intended to inform further development and refinement of the methods utilized in the study, including questionnaire content, components of the intervention, and topics explored in the embedded qualitative research [50].

The protocol covers the 3 aims of the study. The first aim is to identify and recruit YBLMSM and YBLTW living in the 3 Mid-Atlantic cities into the prevention and treatment continua. The second aim is to use an embedded randomized controlled trial (RCT) to examine the efficacy of a coach-based MEI to achieve sustained retention and engagement in HIV care among youth living with HIV who are not virally suppressed. The third aim is to use an embedded RCT to examine the efficacy of a coach-based MEI to achieve uptake of and adherence to PrEP and other preventive behaviors (eg, protected sex acts) among youth at elevated risk for HIV infection. Both aims 2 and 3 examine identification, referral, and engagement in substance treatment services. The outline of the study design is shown in Figure 1.

Figure 1. Study flow diagram. MEI: mobile-enhanced intervention; PrEP: pre-exposure prophylaxis; RDS: respondent-driven sampling.

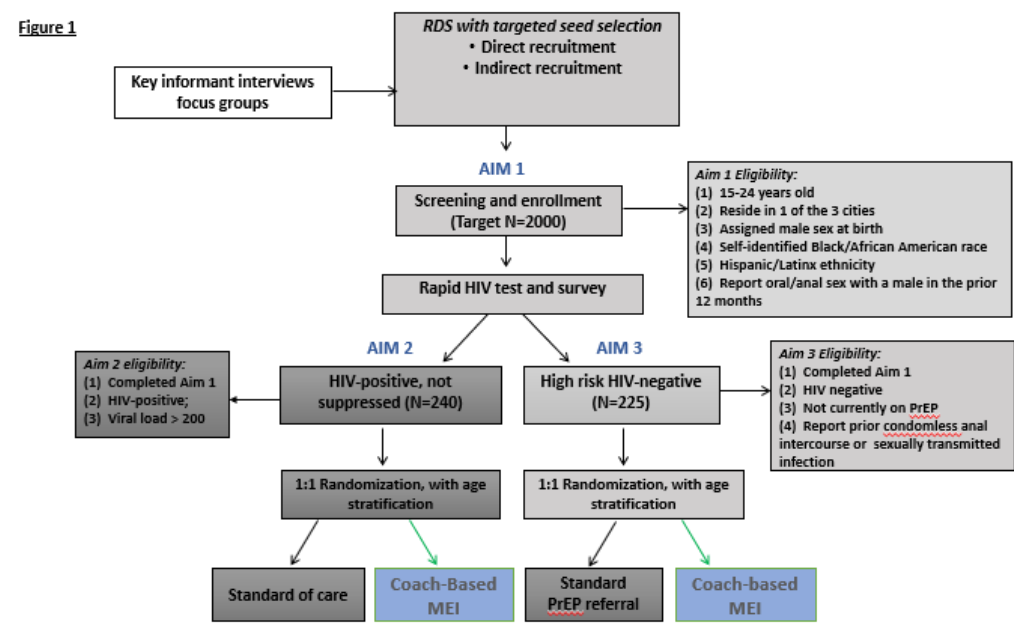

1) 15-24 years old; (2) reside in 1 of the 3 cities; (3) assigned male sex at birth; (4) self-identified Black/African American race; (5) Hispanic/Latinx ethnicity; and (6) report oral/anal sex with a male in the prior 12 months. 


\section{Study Setting}

The study is being conducted in the following US cities: Baltimore, MD (Johns Hopkins University); Philadelphia, PA (CHOP); and Washington, DC (Children's National Hospital and Whitman-Walker Health). Each city experiences high rates of HIV among YBLMSM and YBLTW (aged 15-24 years) [3].

\section{Formative Research Focus Groups and KIIs}

Focus groups and KIIs were used in the formative phase for the purpose of adapting the study tools, identifying key components of the intervention, and developing the intervention structure. The formative phase was conducted between February 2017 and May 2018. First, 3 focus groups were conducted in Baltimore, MD, to modify and adapt an app for the MEI to meet the needs of YBLMSM and YBLTW. Following focus groups, key informants (KIs) were interview-identified across all 3 cities to inform the refinement of the interventions proposed by the focus groups and to identify topics to be explored in the qualitative interviews.

\section{Formative Research Study Sample}

Participants in the focus groups were eligible to participate if they currently resided or worked in Baltimore, MD, were aged 15 to 24 years, and either self-identified as YBLMSM or YBLTW. Participants of focus groups were recruited through flyer advertisements or provider referrals. KIs and focus group participants were reimbursed US \$35 for participating. KIs included young adults with either a social or mentoring role in the community or someone who worked as a case manager, community outreach specialist, or volunteer. KIs were eligible to participate if they currently resided or worked in Baltimore, MD; Philadelphia, PA; or Washington, DC, and were identified by LGBTQ-serving organizations as persons who were in or around the target age range (18-24 years) and served as YBLMSM and YBLTW or a part of the community. Organizations who referred to KIs were asked to confirm that the KIs fit the eligibility criteria of the study.

\section{Data Collection for Formative Research}

The 3 focus groups lasted for 45 to $60 \mathrm{~min}$ and occurred in Baltimore, MD, only, with an average of 3 participants per group. Facilitation of the focus groups was done in collaboration with emocha Health Inc, a Baltimore-based company that assisted with the development of the mobile app. The goal of the focus groups was to identify key areas of focus for the intervention, mobile app components, and to elicit feedback on wireframes (Figure 2). Wireframes were based on areas developed by emocha Health, Inc for other adherence studies at a seventh-grade literacy level or lower [51]. Additional feedback was provided by an established sexual minority youth advisory board at the Philadelphia site.

Figure 2. Wireframe of mobile app. MEI: mobile-enhanced intervention; PCP: Primary Care Provider.

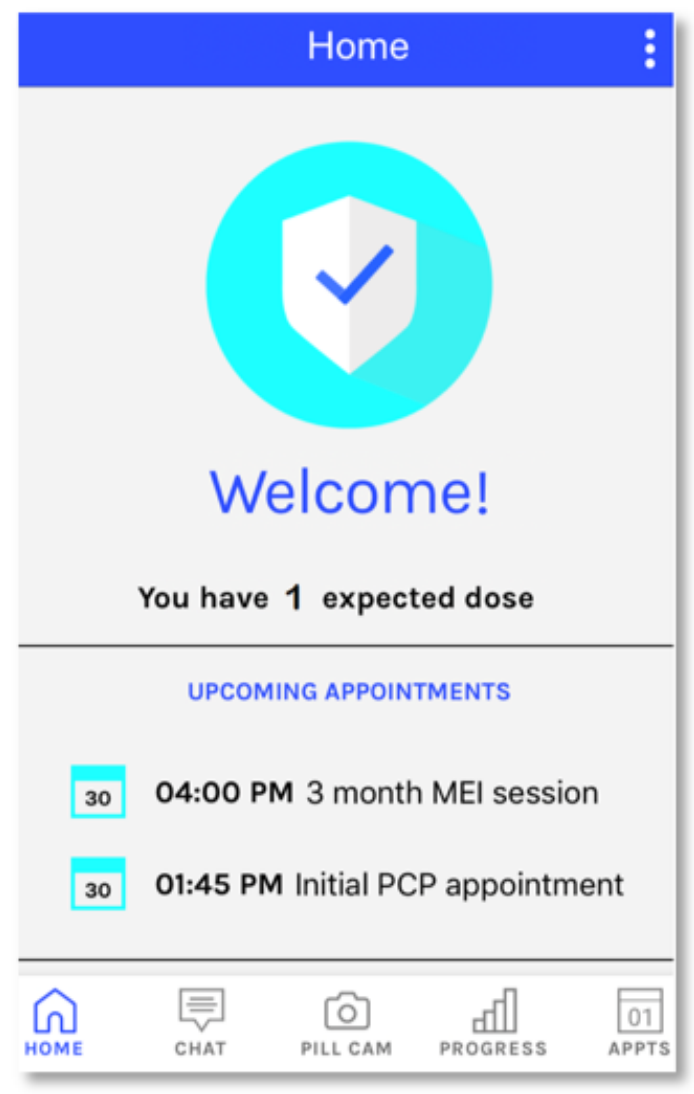

KIs elicited feedback about the intervention from youth or service providers from all 3 cities. The one-time, face-to-face, video or telephone interview lasted approximately $45 \mathrm{~min}$. Semistructured interview guides were created to facilitate discussion around the topics of community and societal barriers to accessing HIV treatment and prevention among YBLMSM and YBLTW and strategies (eg, navigator, coach, and mobile app) that could be used to address barriers. Participants were then asked to provide feedback on specific components of the mobile app developed by emocha Health, Inc around potential 
use and functionality. Example questions used in the focus groups and KIs included, "Rank the following features that would be helpful to you (or a YBLMSM or YBLTW aged 15 to 24 years) in improving your (their) health and following up with your (their) medical care: (1) goal planning for medications, (2) adherence reminders, (3) adherence support (rewards or points for positive adherence, coach support), (4) pill cam, (5) progress calendar; (6) personalized health information or text messages, and (7) general information (information about testing, condoms, resources, housing, and insurance). Why did you select (insert top choice) as your top choice?"

\section{Data Analysis}

Focus groups and interviews were audio-recorded and transcribed verbatim by an independent transcription company. Initial codes were identified from the interview and focus group guides developed by our research team. The codes were then refined and elaborated during the process of analysis using the constant comparison method [52].

Using a systematic approach to further validate and connect categories continued until the point of data saturation [53]. Grouped and categorized codes were then examined for emergent themes [49]; approximately $10 \%(n=3)$ of transcripts were double-coded and then reviewed for intercoder reliability or consistency to ensure high coder agreement (Kappa>0.80). Transcripts were reviewed using NVivo 11 software and included analyses based on the presence of identified codes and emergent concepts.

A total of 10 youth participated in the focus groups, and $18 \mathrm{KIs}$ participated in formative interviews. Focus group participants suggested that the app include the following components: (1) goal planning for ART adherence and substance use treatment, (2) time reminders, (3) adherence reminders, and (4) adherence support (rewards or points for achieving optimal adherence). Findings from key interviews have been described elsewhere [54]; however, KIs recommended that the study allow for a longer follow-up time (greater than 4 weeks) for coupons to ensure engagement around recruitment, and suggested that the app has rewards for achievement. KIs suggested that the intervention focused on values (health priorities and personal goals), medication initiation and adherence, medical appointments, alcohol or drug use, and sexual health. The KIs suggested that the intervention should be flexible with bidirectional support with a coach, using multiple methods (eg, app, text message, and telephone calls), and the coach must be a peer or close to the population to enhance engagement with the intervention.

\section{Clinical Trial Methods}

\section{Aim 1}

\section{Sample and Setting}

The first aim of this protocol is to identify and recruit YBLMSM and YBLTW who are at risk or living with HIV in Baltimore, MD; Philadelphia, PA; and Washington, DC, using RDS with targeted seed identification. This protocol focuses on participants who are (1) aged 15 to 24 years, (2) reside in the 3 study cities, (3) assigned male sex at birth, (4) self-identified Black/African
American race or Hispanic/Latinx ethnicity, and (5) report oral or anal sex with a male in the prior 12 months. We included youth assigned male sex at birth, including both transgender and gender-expansive youth as well as nonbinary youth, given the gender diversity, dynamic, and fluidity of gender identity during adolescence. In addition, adolescents may be at varying places along the gender transition spectrum and may or may not identify as male or transgender [55].

\section{Recruitment}

Participants are recruited using RDS with targeted seed selection. As part of aim 1, we aimed to compare direct and indirect targeted seed selection methods for reaching at-risk youth (behaviorally at risk for HIV acquisition or living with HIV and virally unsuppressed). Direct seed selection consists of informational flyers directly given to youth from study staff at a clinical site or at a community-based organization or in-person event (eg, house ball, pride, or community informational session). Indirect seed selection consists of informational flyers posted at clinical sites that serve LGBTQ youth or at the offices of community-based organizations. Indirect seed selection also includes a web-based approach that consists of electronic advertisements placed on webpages and social and sexual networking sites frequented by YBLMSM (eg, Jack'd, Black Gay Chat, and Grindr; Figures 3 and 4). A link on the web-based advertisements directs potential participants to the study landing page where they can leave their information for staff to contact them about participating [56]. The staff maintain the page and rotate images frequently to maintain engagement. Staff return all web messages within 48 hours.

RDS is a chain-referral sampling method that is typically used to approximate a probability sample of populations when sampling frames are unavailable [57,58]. For the purpose of this protocol, RDS is used to recruit behaviorally at-risk youth to status-dependent RCTs. Each seed was asked to participate in the study and to invite up to 5 peers from the target population to be screened for study eligibility. Unlike other HIV research, our goal is not to approximate a probability sample to produce population-based estimates but to investigate associations with risk behaviors and to identify participants who could be enrolled in the RCTs.

As recommended during formative research, this study uses electronic coupons (e-coupons) to facilitate the distribution of study coupons, given the challenges youth may face in physically meeting with peers to distribute paper coupons (as had been done previously). At the initial visit, a staff member meets with a participant, brainstorms about who to distribute coupons to peers, and provides instructions for the distribution of e-coupons using cell phones. The staff member provides a unique participant web link to the participant, which they then use to send their e-coupon to peers, including friends and social contacts. The link takes the participant to a page where they can see and manage the sharing of their e-coupons with peers. During the visit, the participant is asked to send their e-coupons to their peers (electronic respondent-driven sampling [eRDS] recruit) and to verify receipt. The eRDS recruit (a person receiving the e-coupon) receives a text message informing them 
that they have been invited to participate in a research study. The text message includes a unique numeric code, study telephone number, study site operating hours, and an expiration date (approximately 2 weeks after issuance). The recruit then contacts the study team to set up an appointment at the study site, at which point they are asked to provide their e-coupon to staff to initiate eligibility screening. The unique numeric code of the e-coupons permits the identification of linkages between seeds or recruiters and recruits in the data. E-coupons omit any sensitive information about participating in an HIV-related study, though seeds or recruiters and peers can discuss this verbally. Participants who are unable to distribute e-coupons or who choose not to use e-coupons are provided paper coupons for distribution.

Figure 3. Web-based Flyer.

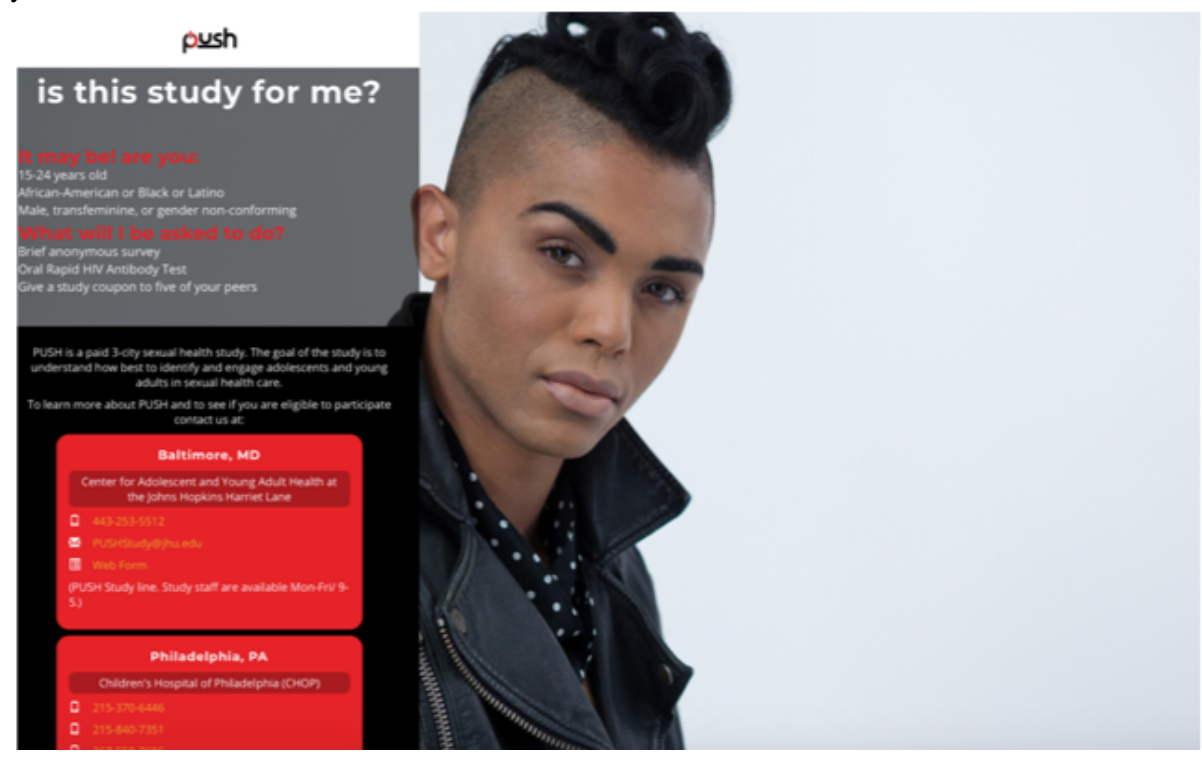

Figure 4. Example of Facebook/Instagram.

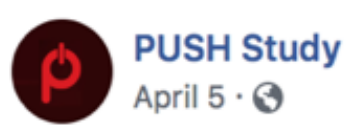

Help us test our health app! Message us to see if you qualify and how to get involved.

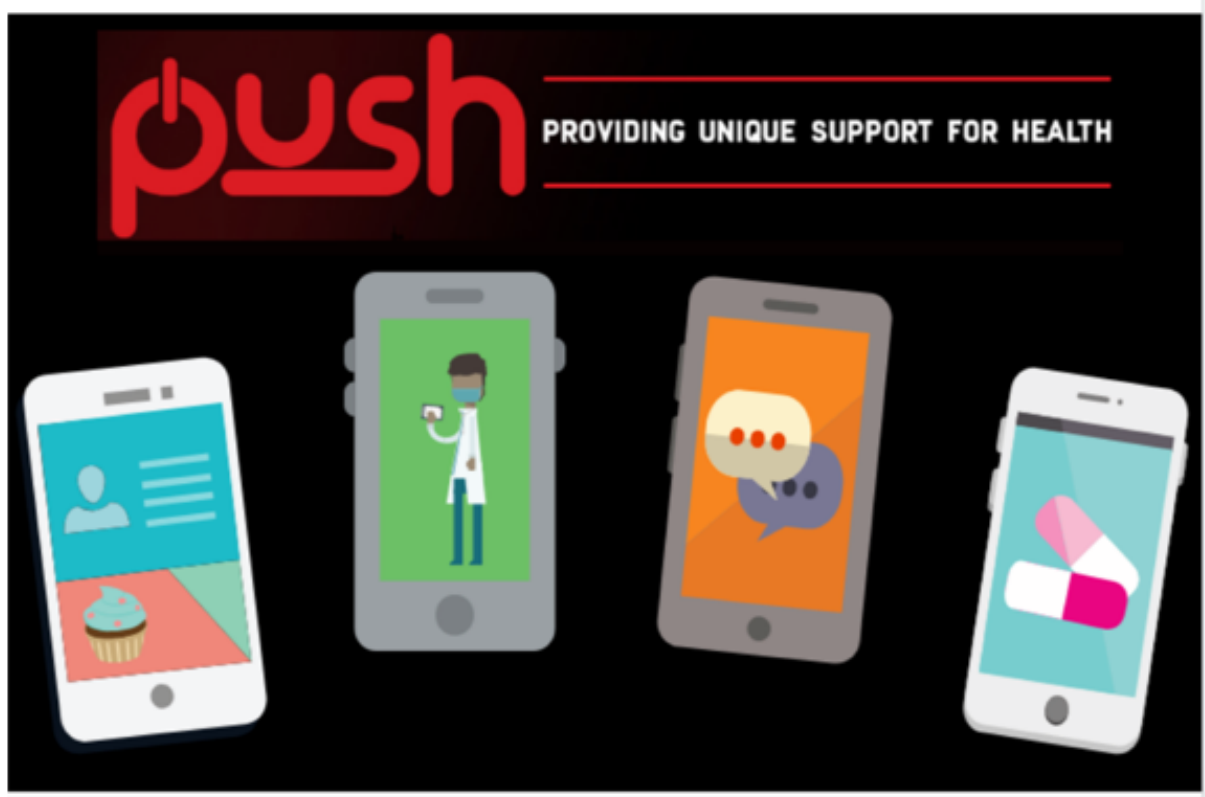

\section{Study Activities}

Participants, including both seeds and recruits, are provided the opportunity to complete a survey and a rapid HIV testing
(OraQuick Advance or INSTI). The survey includes measures of key demographics, social network characteristics, HIV testing and diagnosis history, substance use, and history of PrEP use 
(Textbox 1). Skip patterns are used to reduce the number and complexity of the questions. All data measures are captured in the same data system that is designed for RDS data collection and tracking. Data are tracked with a unique study ID only and are not associated with participant contact information.
Participants are asked to return in 2 weeks for coupon payment, to complete a second survey that asks about their social network and in what context coupons are provided, and to participate in a booster RDS training where they spend additional time with staff reviewing techniques and strategies to promote the distribution of coupons [59]. Participants are reimbursed US $\$ 5-15$ per peer recruited peer (dependent on site).

Textbox 1. Study domains and measures.

\section{Demographic measures}

- Age, gender identity, marital status, education, annual income, race and ethnicity, health insurance status, housing, and employment status

\section{Respondent-driven sampling}

- Network size and characteristics, utilized for respondent-driven sampling weighting

\section{Internet or mobile phone use}

- Type of phone, data plan, and frequency of use; loss of plan; and other family members who have access to the phone

Venue use

- Information on physical venues where participants frequent will be collected; venues will be included to assess overlap between physical and web-based seed networks

\section{HIV testing and care history}

- Frequency of HIV testing in the past year, date of most recent HIV test, and receipt of HIV test results

\section{HIV continuum}

- Self-reporting HIV infection; current engagement in care, including antiretroviral treatment; adherence; and self-reported viral load status

Knowledge of pre-exposure prophylaxis (PrEP) and postexposure prophylaxis (PEP)

- $\quad$ Knowledge, perception of, and history of PrEP and PEP use

Sexual matrix module and sexual risk behavior

- Sexual attraction, identity, and behavior; 7-item question HIV Incidence Risk Index for men who have sex with men (MSM) males only [60,61]; information on number of partners and frequency and types of sexual acts; network of the sexual contacts; location of where sexual experiences occurred; and perceived sexual risk for sexually transmitted infections, including risk for HIV

\section{Health care use}

- Health care and services utilization and engagement and trust between the clinician and patient

\section{Stigma and mental health}

- $\quad$ Self-stigma (internalized homo-negativity) and HIV stigma (with consideration of impact on HIV testing and adherence) adapted from Herek et al $[62,63]$; mental health will include lifetime and recent history of depressive symptoms and anxiety, using the Patient Health Questionnaire-4 [64], post-traumatic stress disorder (Child Post-Traumatic Stress Disorder Symptom Scale) [65], and experiences of discrimination [66]

\section{Social environment}

- Outness Inventory [67]; intimate partner violence, victimization, and perpetration (Safe Dates instrument) [68]; sexual guilt (Revised Mosher Sex-Guilt Scale) [69]; lesbian, gay, bisexual, transgender, and questioning (LGBTQ) victimization [70]; and social context (perceived parental support and religious environment) [71]

\section{Substance use}

- Car, relax, alone, forget, friends, and trouble (CRAFFT) six-item substance use screen and a modified Time Line Followback assessing days of use of various substances [72,73]

Engagement in the lesbian, gay, bisexual, transgender, queer (LGBTQ) community

- Measures of strength of engagement and connection in the LGBTQ community 


\section{Coach-Based MEI for Youth Living With HIV}

The second aim of the protocol is an RCT to examine the efficacy of a mobile-enhanced coach-based intervention to achieve sustained retention and engagement in HIV care among youth living with HIV who are not virally suppressed.

\section{$\operatorname{Aim} 2$}

\section{Study Sample}

YBLMSM or YBLTW, recruited into aim 1, who are identified as HIV-positive (previously diagnosed with HIV-self-report of HIV-1 and confirmed viral load, or newly diagnosed-no prior history of HIV and rapid HIV test positive) are invited to participate in the RCT of aim 2 of the study. Additional eligibility includes not virally suppressed; no plan to relocate in the next 18 months; not enrolled in another HIV treatment intervention; and currently own or have access to a cell phone, private tablet, or laptop. Potential participants are provided information about the study, consented, and a blood sample for the viral load is obtained (if no recent viral load within 3 months was documented in the medical chart). Participants with an HIV-1 viral load $>200$ copies/mL are eligible to participate in aim 2. We aim to recruit 240 YBLMSM or YBLTW living with HIV who are not virally suppressed.

\section{Study Procedures}

After enrollment, participants complete a baseline survey and are randomized (1:1) to 1 of 2 study arms: coach-based MEI or SOC. Randomization to the intervention arms is stratified by site; age group, to yield a balanced randomization between younger (aged 15-19 years) and older (aged 20-24 years) age groups; and enrollment site.

\section{SOC}

Participants randomly assigned to the SOC arm are provided information about and referrals for HIV care and/or prevention. They return to the research setting every 3 months to complete surveys and conversation with assigned study personnel. The focus is on active listening, with no attempts to direct goal setting; screening, brief intervention, and referral to treatment (SBIRT); or motivational interviewing (MI), as discussed below. Personnel are encouraged to refer to local clinical resources, help with participant care navigation, and case management services at each follow-up visit, as needed.

\section{Coach-Based MEI}

The coached-based MEI is a tailored and enhanced case management strategy that serves as the primary intervention for participants with unsuppressed HIV viral load. Individuals randomized to the coached-based MEI receive weekly telephonic and app-based support and a structured face-to-face meeting every 3 months, augmented by the ongoing implementation of the study's mobile app. Telephonic and in-person supportive consultations are goal focused and designed to enhance linkage, ART initiation, adherence, and retention in care for MSM diagnosed with HIV [74-76]. The MEI coach is trained in and utilizes Rogerian listening skills, MI, SBIRT for substance use, and personal health goal setting to best support assigned participants [77-81]. It is based on the case management protocol 078 of the HIV Prevention Trials Network (HPTN) [82], emphasizing routine engagement around health behaviors and goals. To meet the needs of youth, the team modified the approach to adapt it for YBLMSM and YBLTW living with HIV and to incorporate the mobile app and MI components.

\section{Training and Selection}

MEI coaches were hired based on previous work experience in the MSM community, HIV services (eg, outreach, testing, and case management), interest in aiding research, and ability to communicate effectively with the target population. Representation of the MSM, Black, and Latinx communities was encouraged in the job posting process.

MEI coaches received an initial intensive 16-hour training including (1) introduction to study (2 hours); (2) developmental considerations in cognitive and emotional processing in teens and young adults (1 hour); (3) barriers to PrEP uptake, HIV ART adherence, and HIV risk reduction (1 hour); (4) SBIRT, including screening tools for alcohol and drug use, and effective interviewing about substance use (1 hour); (5) discussion on cultural competence and social determinants of health in case management with YBLMSM and YBLTW (1 hour); (6) mobile app and encouraging engagement with participants (1 hour); (7) study fidelity and data recording expectations (2 hours); (8) didactics and group practice on goal setting and health behavior change (1 hour); and (9) MI components on MI spirit, stages of change, core skills (eg, guiding, open-ended questions, affirmations, reflections, and summarizing), collaborative goal setting, rolling with resistance, and repeated role-play (6 hours).

MEI coaches receive ongoing training and support during their continued involvement in the study. Bi-weekly, hour-long videoconference supervision on MI application, goal setting, and troubleshooting are provided remotely by a psychologist with expertise in MI training, substance use, and HIV care. In-person, telephonic, and app-based participant communications, successes, and barriers are discussed as well as topical trainings based on coach needs, MI skills, goal setting, and substance use. The MEI coaches routinely audio-record face-to-face visits with participants assigned conditions, and the supervising psychologist provides individualized written and verbal feedback on each recording on the use of MI and goal-setting techniques, as applied to the individual's circumstances as well as fidelity to the study intervention.

\section{Study Intervention}

The intervention is administered by a trained MEI coach and includes substance use screening brief interventions and ongoing monitoring throughout the prevention and treatment care cascade [72]. Coaches begin in the initial face-to-face visit with building rapport, explaining the intervention, and identifying personal and health goals. Health goals focus on medication adherence, health care engagement and satisfaction, substance use, and sexual health. Coaches then map out and help the participant prioritize each goal. After the initial question-answer period and establishment of goals, the MEI coach develops an individually tailored plan that is designed to utilize self-determination theory [83] and the Integrated Theory of Health Behavior Change [84] to facilitate the adoption and maintenance of health behaviors. The approach is centered on identified participant goals and values and care engagement, 
utilizing a card-sort procedure to help prioritize participant goals for each session [77]. Participants who score positive on the CRAFFT (car, relax, alone, forget, friends, and trouble) and Alcohol, Smoking, and Substance Involvement Screening Test are provided with prevention psycho-education around substance use risks $[72,73,85]$. Participants who score 2 to 3 on the CRAFFT are encouraged to develop a change plan to reduce substance use and scheduled for additional intervention sessions. These cutoffs were used because a CRAFFT score of 2 or higher is optimal for identifying any substance-related problem and an SUD (according to the Diagnostic and Statistical Manual of Mental Disorders, 5th Edition criteria) [86]. Coaches subsequently attempt to link participants who score above 4 to substance use services. Participants who describe sexual risk (eg, condomless anal sex) are also provided psycho-education around sexual risk and PrEP. Coaches help participants develop strategies to avoid substance use and sexual risks in the future.

At the core of the coached-based MEI approach are supportive services such as navigation, adherence counseling, and tailored support for care engagement and treatment adherence for persons living with HIV. This intervention focuses on 3 steps in the support process: MyCare (steps 1 and 2) and MyHealth (step 3). Participants who are living with HIV start with MyCare (step 1) to support the decision to (re-)initiate HIV care. This includes the use of MI to help orient the client toward seeking and initiating care. MyCare (step 1), which is modeled after life steps, a single-session intervention grounded in cognitive-behavioral principles, is at the core of several successful ART adherence interventions [12,87,88]. MyCare (step 2) adds to this evidence-based approach by recognizing that adherence to medications is a personal choice grounded in a variety of behavioral and psychosocial domains. MyHealth (step 3) is based on the premise that a patient engaged in self-management and supportive strategies will feel empowered to take ownership of their own health care needs.

The face-to-face visits consequently address psycho-education about HIV risk, HIV and ART, planning and problem-solving to access and maintain a steady supply of medication, formulating a daily medication schedule, cues for pill-taking, coping with side effects and/or other participant concerns, developing a plan to mitigate side effects and responses to slips in adherence (if applicable), and engaging around condom use and/or limiting sexual risk behaviors. Counseling is tailored to the participants' specific needs and case management or navigation needed.

Telephonic and app-based check-ins between the MEI coach and participants are conducted to maintain rapport, open communication, review progress on personally identified goals, help troubleshoot challenges that may arise, and provide reminders for upcoming face-to-face visits. The app is used to facilitate communication around medication adherence, medical visit completion, video chat, and bidirectional communication. The MEI coach will determine the participant's desire for support, and the frequency and schedule of messages. It is the aspirational goal of the study to have the MEI coach have weekly contact with participants; however, this is often not realistic for all participants. For example, some participants will embrace weekly check-ins, others prefer to engage more intermittently, and the remaining participants may experience situational or motivational barriers that may interfere with engagement. MEI coaches may need to utilize MI strategies to explore readiness to engage in telephonic check-ins and study visits and troubleshoot barriers that may arise (Table 1), and re-engagement needs to be pursued by the MEI coach. MEI coaches seek to check-in with participants weekly (at a minimum), and participants are encouraged to attend face-to-face follow-up coach visits at 3, 6, and 12 months. During these face-to-face visits, coaches will work with the participant to review, motivate, and reinforce personal life events, health care engagement, review substance and risk reduction goals, and problem-solve. Using this MI approach, the participant is thus empowered to take the lead with recommendations and guidance from the MEI coach. Permission is sought to audio-record each initial and follow-up study visit for the purpose of assessing study fidelity and providing routine, ongoing feedback to the MEI coach. The recording is at the discretion and informed consent of the participant and the MEI coach. Ad hoc telephonic and in-person support is also provided by the MEI coach, as requested by the participant. An MEI coach, at any time may help, for example, with referral to behavioral health, job resources, community support resources (eg, a food bank), provide supportive listing, or help arrange any requested sexually transmitted infection testing.

Table 1. Motivational interviewing approaches to address level of interest in telephonic engagement.

\begin{tabular}{|c|c|c|}
\hline Participant comments & Stage of change & MEI $^{\mathrm{a}}$ coach approach \\
\hline $\begin{array}{l}\text { Agreement: "Sure, I wouldn't mind } \\
\text { texting each week." }\end{array}$ & Action & $\begin{array}{l}\text { Reinforcement, summarize: "Great, I will make sure I will check-in by text each week, } \\
\text { or more if wanted by you." }\end{array}$ \\
\hline $\begin{array}{l}\text { Barrier: "That would be good, but } \\
\text { my phone sometimes cutoffs if I } \\
\text { don't make my bill." }\end{array}$ & Determination & $\begin{array}{l}\text { Summarize, empower: "I understand. I will try to text each week, and occasionally you } \\
\text { may not have cell service. Any ideas of what we could do to stay in touch if your phone } \\
\text { loses service?" }\end{array}$ \\
\hline $\begin{array}{l}\text { Ambivalence: "I'm not sure, I mean } \\
\text { I wouldn't mind, I guess." }\end{array}$ & Contemplation & $\begin{array}{l}\text { Paraphrase, elicit, affirm: "I hear you might be willing to consider this, and you might } \\
\text { not be sure... (Pause...momentary wait...and follow-up if no response)... I have definitely } \\
\text { worked with some people who were wary about the check-ins, is there anything about } \\
\text { this you might not be thrilled about?" }\end{array}$ \\
\hline
\end{tabular}

${ }^{\mathrm{a}}$ MEI: mobile-enhanced intervention. 


\section{Fidelity}

Face-to-face coached-based MEI visits will be recorded. A standardized fidelity checklist will be utilized by the supervising psychologist to quantify discussion of topic domains, rating the domains on a 3 -item Likert scale $(0=$ none, $1=$ partial discussion, and 2 =focused discussion) with provided anchors. The domains for coverage during an MEI coach visit are (1) taking medication as prescribed, (2) attending medical appointments, (3) experience at the health provider's office, (4) encouraging participants' use of the MEI mobile app, (5) participant's actual engagement with the mobile app, (6) alcohol or drug use, (7) sexual health, and (8) role of values in participants' health decision making. A total of $20 \%$ of all recorded visits will be reviewed for overall fidelity, seeking a representative sample across MEI coaches, and follow-up visits (eg, baseline and 3-months) across the course of the study. Interrater reliability will be conducted by a coworker of the supervising psychologist trained in the intervention and research methods. MEI coaches will also complete their own fidelity assessment after each MEI coach face-to-face visit, which will help to regularly refresh and reinforce the core elements of each study visit. Data will also be collected from study participants about what topics were covered in their study visits. MEI coaches will also log all study contact with each participant on a secured study record, allowing for monitoring and feedback on the frequency of telephonic encounters.

\section{Coach-Based MEI for Youth at Risk for HIV}

The third aim is to use an RCT to examine the efficacy of a mobile-enhanced coach-based intervention to achieve uptake of and adherence to PrEP and other preventive behaviors (eg, protected sex acts) among youth at elevated risk of HIV infection.

\section{Aim 3}

\section{Study Sample}

This sample will be composed of YBLMSM or YBLTW recruited into aim 1, who test negative for HIV but are not currently on PrEP, and report either engaging in condomless anal intercourse or a prior history of a sexually transmitted infection. Additional eligibility includes no plan to relocate in the next 18 months; not enrolled in another PrEP behavioral intervention; and currently own or have access to a cell phone, private tablet, or laptop. Potential participants are provided information about the study and must consent to participate. We aim to recruit 225 YBLMSM or YBLTW at risk for HIV.

\section{Study Procedures}

After enrollment, participants complete a baseline survey and are randomized (1:1) to 1 of 2 study arms: coached-based MEI or SOC. Randomization to the intervention arms is stratified by site; age group, to yield a balanced randomization between younger (aged 15-19 years) and older (aged 20-24 years) age groups; and the enrollment city. After each participant is identified, they are provided with their assigned treatment assignment.

\section{SOC}

Participants randomly assigned to the SOC arm in the at risk for HIV group receive a similar structure as those with uncontrolled HIV. Initially, they are provided information about HIV prevention strategies and the schedule for follow-up data assessments. During quarterly meetings, a brief check-in conversation and active listening is conducted without the use of SBIRT, MI, or goal-setting, and participants are referred, if needed, to local clinical or community assistive and services at each follow-up visit.

\section{MEI Coach Intervention}

The focus of the Providing Unique Support for Health (PUSH) study is to engage individuals at risk for HIV into prevention and care. The approach is the same as aim 2, modeled after life steps $[12,87,88]$ and based on the case management protocol 078 of the HPTN [82]. It is tailored to the prevention needs of the youth. As such, during the first step, the coach uses MI to orient participants and increase their readiness for preventive engagement. The counseling session addresses psycho-education about HIV risk; planning and problem-solving for mitigating risk, including addressing coexisting substance use; coping with side effects and adherence of PrEP; and/or other participant concerns, developing a plan to address slips in PrEP adherence (if applicable) or condom use. Coaching is tailored to the participants' specific needs and case management or navigation needed. As with the second aim, randomly assigned participants will be requested to meet with their MEI coach every 3 months and have weekly telephonic check-ins, to review progress on personal goals, risk reduction, and help to troubleshoot factors that may increase HIV risk or personal goals. The MEI coach will utilize MI, SBIRT, active listening, and goal-setting in face-to-face visits, and telephonically will check-in on their lives, their goal progress, and app usage. MI strategies will be utilized to address motivational and situational barriers to study engagement in person or telephonically (Table 1).

Similar to the second aim, this MEI coach intervention focuses on 3 steps in the support process: MyCare (Steps 1 and 2) and MyHealth (step 3). MyCare (Step 2) adds to this evidence-based approach by recognizing that uptake of PrEP or prevention services is a personal choice grounded in a variety of behavioral and psychosocial domains. MyHealth is based on the premise that a patient engaged in self-management and supportive strategies will feel empowered to take ownership of their own health care needs. The MEI coach will determine the participant's desire for support and the frequency and schedule of messages. For example, some participants embrace engagement intermittently, whereas other participants delay engagement and need to be taken through the engagement steps again. Participants are provided with as much or as little coaching as needed using this flexible approach, but the MEI coach will check-in with participants telephonically weekly (at a minimum), and participants are requested to attend face-to-face follow-up coach visits at 3, 6, and 12 months. During these visits, the coach will review participant's progress toward personal and health goals, motivate and reinforce treatment engagement, review substance and risk reduction goals, and help problem-solve any obstacles that may have arisen. Using 
this approach, the participant is thus empowered to take the lead with recommendations and guidance from the MEI coach. Participants receive ongoing screening for sexual risk and substance use, and the coach's approach is modified based on self-reported needs.

The study infrastructure for supporting and maintaining the MEI coach will be duplicated for the third aim. MEI coaches will receive remote bi-weekly support, instruction, troubleshooting, and feedback from the supervising psychologist, focusing on the delivery of MI, goal-setting, and SBIRT. Audiotaped recordings will be conducted during face-to-face visits, with the informed consent of the participant and discretion of the MEI coach, and will be reviewed by the supervising psychologist for feedback and assistance to the MEI coach and to track study fidelity. Likewise, participants and MEI coaches will complete fidelity assessments postvisit to reinforce study aims, prevent intervention drift, and provide additional data about the intervention delivered.

\section{Data Collection for Aims 2 and 3}

The PUSH study uses a built-in randomization engine adapted from previous studies [89]. The allocation between intervention and control arms is determined randomly by the engine, where each round comprises 2 intervention and 2 control assignments that are linked to the stratification factors of site and age group. Once a round is completed, a new round begins.

Participants are asked to participate in research visits at $0,3,6$, 9, 12, and 18 months (exit interview). This visit schedule aims to ensure frequent contact and to minimize attrition. Laboratories and study-related activities are described in Table 2. Surveys provided at baseline (Textbox 1) are re-administered at each follow-up with additional questions focused on ART, PrEP, barriers, and facilitators to adherence.

Table 2. Study visits and associated laboratory tests.

\begin{tabular}{|c|c|c|c|c|c|c|}
\hline \multirow[t]{2}{*}{ Tasks } & \multicolumn{6}{|l|}{ Visits } \\
\hline & Baseline & 3 months & 6 months & 9 months $^{\mathrm{a}}$ & 12 months & 18 months \\
\hline Complete a survey & $\varsigma^{\mathrm{b}}$ & $\checkmark$ & $\checkmark$ & $\checkmark$ & $\checkmark$ & Exit interview \\
\hline $\begin{array}{l}\text { Provide blood for HIV-1 RNA viral load testing } \\
\text { (aim 2) or HIV-1 antibody testing (aim 3) }\end{array}$ & $\checkmark$ & $\checkmark$ & $\checkmark$ & $-^{\mathrm{c}}$ & $\checkmark$ & - \\
\hline Provide urine for drug testing & $\checkmark$ & $\checkmark$ & $\checkmark$ & - & $\checkmark$ & - \\
\hline Update locator information & $\checkmark$ & $\checkmark$ & $\checkmark$ & $\checkmark$ & $\checkmark$ & - \\
\hline Meet with MEI $^{\mathrm{d}}$ coach (intervention only) & $\checkmark$ & $\checkmark$ & $\checkmark$ & $\checkmark$ & $\checkmark$ & $\checkmark$ \\
\hline Medical chart review (research staff only) & $\checkmark$ & $\checkmark$ & $\checkmark$ & $\checkmark$ & $\checkmark$ & $\checkmark$ \\
\hline Compensation, US \$ & 50 & 50 & 50 & $\begin{array}{l}10 \text { check-in via } \\
\text { phone; } 25 \text { survey }\end{array}$ & 50 & 25 \\
\hline $\begin{array}{l}\text { Participate in an in-depth interview (selected partic- } \\
\text { ipants) }\end{array}$ & $\checkmark$ & - & $\checkmark$ & - & $\checkmark$ & - \\
\hline Compensation, US \$ & 25 & - & 25 & - & 25 & - \\
\hline
\end{tabular}

${ }^{\mathrm{a}} 9$-month visit constitutes either a brief phone check-in ( $5 \mathrm{~min}$ ) or in-person survey (15 min).

${ }^{\mathrm{b}}$ Data collected at this time point.

${ }^{\mathrm{c}}$ Data not collected at this time point.

${ }^{\mathrm{d}}$ MEI: mobile-enhanced intervention.

\section{Sample Size Considerations}

We aim to recruit up to 2000 YBLMSM and YBLTW to be screened for eligibility for aims 2 and 3 . We conservatively estimate that $15.00 \%$ of the RDS recruited sample will be HIV-infected and not virally suppressed, given an HIV prevalence of $25 \%$ to $40 \%$ among YBLMSM and YBLTW across the sites and as many as $60 \%$ of HIV-infected YBLMSM are undiagnosed $[4,9]$.

We expect a $15.0 \%$ loss to follow-up over 1 year in aim 2 . Starting with $\mathrm{n}=240$ will yield an effective sample size of 204 individuals in total, or 102 in each group, available for analysis in aim 2. A total estimate of $n=200$ will be enough to detect an average increase in the viral suppression proportion over the 3 follow-up visits of $16.0 \%$ from $24.0 \%$ assumed in the control arm to $40.0 \%$ in the coached-based MEI arm (odds ratio, OR
2.03 ), assuming a power of $85.0 \%$. We expect a slightly greater loss to follow-up (20.0\% loss to follow-up) in participants in aim 3. Starting with $n=225$ will yield an effective sample size of 180 individuals in total or 90 in each group. We estimate that a total of 180 participants ( 90 per group), and assuming a $15.0 \%$ average rate on PrEP in the control arm, we can detect an average increase of $14.0 \%$ to $29.0 \%$ (OR 2.31) with power $85.0 \%$. Lost to follow-up estimates are based on the team's prior work with this population.

\section{Data Analysis}

Aim 1 analyses are descriptive and include baseline characteristics related to sociodemographic characteristics, HIV infection, and sexual behavior of the YBLMSM and YBLTW samples across all sites as well as stratified by site. Descriptive tables with unweighted estimates and Pearson chi-squared tests 
for significance are used to compare age, web-use and venue attendance, and other characteristics of each recruited seed type.

To compare the efficiency of seeds from direct versus indirect seed selection in the recruitment of HIV-positive or at-risk youth, we use the RDS statistical package developed by Schonlau and Liebau [90]. This permits an assessment of the overlap of networks across seed types and across recruitment sites. Efficiency is assessed through recruitment diagnostics, including coupon return rate, homophily, the mean number of recruits, and recruitment depth per seed type. This approach also allows us to assess the time from recruitment activation through the achievement of target sample size and response rates. RDS weights will not be utilized in these analyses, as this aim focuses on descriptive sample proportions rather than producing population-based estimates. We will also examine the networks described by younger (aged 15-19 years) and older (aged 20-24 years) participants recruited from different seeds and use similar methods to understand the overlap of age groups across different networks.

The primary outcome for aim 2 is durable viral suppression (HIV viral load<200 copies/mL), and the secondary outcome is retention in HIV care (defined as documented 2 or more follow-up medical visits over 12 months, treated as a dichotomous variable). The primary outcome for aim 3 is self-reported PrEP use over 12 months in PrEP users, and the secondary outcome is self-reported condom use in PrEP nonusers. The overall approach is based on an intention-to-treat analysis with treatment assignment (eg, coached-based MEI vs SOC) being the primary independent variable for all models.

The success of the randomization process is measured by comparing the distribution of participant characteristics between the 2 groups at baseline. If the randomization process does not result in comparable groups, adjustment is made for group differences in the multivariable models. For aim 2, logistic regression is used to examine whether participants who receive MEI coach are more likely to be virally suppressed as well as retained and engaged in HIV care than participants in the SOC arm. Generalized estimating equations (GEE) are used to determine whether treatment assignment predicts differences in retention for the coached-based MEI versus the SOC groups using repeated measurements over a 12-month period. GEE is used for the longitudinal data as it adjusts for the intra-personal correlation of repeated measurements on the same individual and provides an estimate of the standard error that is robust to misspecification of this correlation structure.

For aim 3, to evaluate whether YBLMSM and YBLTW receiving coached-based MEI have greater uptake of PrEP over 12-months, a survival model is used to examine whether intervention assignment is associated with time to PrEP use. GEE is used to determine whether treatment assignment predicts differences in PrEP utilization and adherence over time for the coached-based MEI versus SOC groups using the repeated measures over the 12-month period [91]. For both aims, we explore trends in uptake and adherence to treatment or PrEP for the intervention group compared with the control group by including an interaction term between time from randomization and treatment assignment.
Going beyond the intention-to-treat approach, we will develop multivariate models stratified by age group (aged 15-19 years and 20-24 years) and include potential confounders and predictors such as prior exposure to case management and PrEP, sexual risk (low vs high), and other demographic variables. Additional models will be evaluated for possible dose-response relationships considering a measure of the level of engagement with the intervention and the frequency of app use. We will assess whether receiving coached-based MEI results in decreased substance use severity, by examining changes in mean CRAFFT scores (a measure of substance use severity) over time for the intervention group compared with the control group for each aim. CRAFFT scores will be treated as continuous dependent variables, and the models will adjust for intra-personal correlations between repeated measurements. Multivariate linear regression will be used to test for decreased severity at each follow-up visit, while controlling for identified confounders.

Modeling techniques have been selected based on the capacity to adequately handle the missingness of data. GEE models assume that the missingness is because of a missing at the random mechanism, which is a restrictive assumption. To address dropout, we use inverse probability weighting to relax this assumption of missing at random [92,93]. Other types of missing data will be handled using multiple imputations.

\section{In-Depth Interviews}

In-depth interviews are completed as part of routine follow-up visits (Table 2). Target enrollment for interviews is 6 participants (3 SOC and $3 \mathrm{MEI}$ ) per aim per site (total of 36). This total will be sufficient to reach informational redundancy across the 3 cities [53]. Interviews focus primarily on changes in self-reported sexual orientation and gender identity, mentorship and community experiences, health care navigation, barriers or facilitators to care or research, and substance use specific to YBLMSM and YBLTW. Initial analysis of the interview data follows the same procedure outlined in the formative data section.

Further analysis will allow for responses and interview themes to be compared across sites, time, participant's age, and other sociodemographic characteristics. The findings are presented to the team on an ongoing basis to provide insight into barriers and facilitators of engagement and intervention experiences over time. Participants are paid US \$25 for each interview.

\section{Consent and Human Subjects Considerations}

Participants in this study go through a verbal consent process (paper or electronic) to enter the formative research, RDS survey, and/or enroll in the RCTs. Electronic consent displays on the screen before the web-based survey. Participants are prompted to provide their signature on the screen as an acknowledgment of consent. This study has obtained a waiver of parental permission for unaccompanied participants and adolescents seeking confidential services who are aged 15 to 17 years under 45 CFR Part 46.408(c), which is in line with local laws in (Maryland HG Section 20-102), Pennsylvania law (IRB SOP 505; Minors' Consent Act, 35, PS 10101), and Washington DC law (code 600.7). For youth aged 15 to 17 years 
recruited through RDS that are not seeking confidential services, we will use advocates (trained social workers) who are independent counselors to work with each participant aged 15 to 17 years before and during the informed consent to ensure adequate comprehension of risks and benefits of participating in the research in Baltimore.

To provide adolescents with additional protections, a certificate of confidentiality has been obtained from the National Institutes of Drug Abuse (NIDA). All staff are trained on confidentiality, HIPAA (Health Insurance Portability and Accountability Act) privacy protections, cultural competency, adolescent counseling techniques, pre- and posttest counseling, mandated reporting, statutory rape laws (specific to the local context), and managing situations of child or sexual abuse. Adolescents who describe physical or sexual abuse or express concerns about mental health are linked to child protective or social work services to ensure their safety. This study was approved by the CHOP, the Children's National Hospital, and the Johns Hopkins School of Public Health institutional review boards.

\section{Results}

A total of 585 participants have been screened to date, with 450 (76.9\%) enrolled. Recruitment monitoring showed that seed propagation was slow and reached low depths, frequently ranging from 1 to 3 waves of recruitment before stopping.

Table 3 summarizes the key demographic characteristics and reported substance use of baseline participants $(\mathrm{N}=402)$ and those who enrolled in aim $2(n=36)$ and aim $3(n=123)$. In summary, the median age was 21.6 years at enrollment, most participants identify as African American/Black (76.6\%), 41 (10.2\%) identify as transgender or female, 145 (41.5\%) completed high school, and $145(36.1 \%)$ had at least some college or technical education. One-quarter $(97 / 402,24.1 \%)$ reported having been without a place to stay in the last year, and most participants reported a history of substance use: alcohol (77.6\%); cannabis (76.6\%); and about a fifth reported use of other drugs including opioids, amphetamine, and cocaine $(21.9 \%)$. Almost a quarter $(n=100)$ reported engaging in transactional sex for a place to stay, money, or food. Moreover, $10 \%$ of the participants described having been forced to do something sexually (coerced sex, $n=40)$ and $10.8 \%(n=43)$ described being forced not to use a condom during sex. Qualitative research is also ongoing. A total of 19 baseline interviews have been conducted within the 3 sites, with 9 interviews from aim 2 participants and 10 interviews from aim 3 participants. 
Table 3. Demographic characteristics and substance use at baseline for participants.

\begin{tabular}{llll}
\hline Characteristics & AMSAB $^{\mathrm{a}}$ participants $(\mathrm{N}=402)$ & \multicolumn{2}{c}{ Participants in aim 2 (n=36) } \\
\hline Age (years), median (IQR) & $21.6(19.3-23.5)$ & $22.9(19.8-23.9)$ & \\
Age category (years), $\mathbf{n}(\%)$ & & & \\
$15-17$ & $42(10.4)$ & $3(11.1)$ & $17(13.8)$ \\
$18-24 \mathrm{~s}$ & $360(89.6)$ & $32.9)$ & $106(86.2)$
\end{tabular}

Race, $\mathbf{n}(\%)$

$\begin{array}{ll}\text { Black/African American } & 308(76.6) \\ \text { Black/mixed } & 28(7.0) \\ \text { Latino/Black } & 26(6.5) \\ \text { Hispanic } & 30(7.5) \\ \text { Unknown } & 10(2.5)\end{array}$

$30(83.3)$

$91(74.0)$

$1(2.8)$

6 (4.9)

3 (8.3)

$12(9.8)$

$0(0.0)$

9 (7.3)

Gender, n (\%)

$\begin{array}{ll}\text { Male } & 347(86.3) \\ \text { Transgender } & 28(7.0) \\ \text { Female } & 13(3.2) \\ \text { Gender nonbinary or nonconforming } & 13(3.3)\end{array}$

30 (83.3)

$108(87.8)$

$3(8.3)$

8 (6.5)

2 (5.6)

$1(0.8)$

$1(2.8)$

$6(4.8)$

Sexual identity, n (\%)

$\begin{array}{ll}\text { Gay } & 255(63.4) \\ \text { Bisexual } & 88(21.9) \\ \text { Heterosexual } & 25(6.2) \\ \text { Queer } & 10(2.5) \\ \text { Pansexual } & 9(2.2) \\ \text { Other or questioning or missing } & 33(3.2)\end{array}$

25 (69.4)

86 (69.9)

5 (13.9)

24 (19.5)

$1(2.8)$

5 (4.1)

$0(0.0)$

$4(3.2)$

$2(5.6)$

$2(1.6)$

$3(8.3)$

2 (1.6)

Highest level of education, $n$ (\%)

$\begin{array}{ll}<\text { High school } & 89(22.1) \\ \text { High school graduate } & 167(41.5) \\ >\text { High school } & 145(36.1)\end{array}$

$12(33.3)$

29 (23.6)

$13(36.1)$

50 (40.6)

$10(27.8)$

$44(35.8)$

Are you employed?, n (\%)
Yes
$227(56.5)$
No
$174(43.3)$

17 (47.2)

71 (57.7)

$18(50.0)$

$52(42.2)$

Been without a place to stay in the last 12 months, $\mathbf{n}(\%)$

$\begin{array}{llll}\text { No } & 301(74.9) & 26(72.2) & 103(83.7) \\ \text { Yes } & 97(24.1) & 9(25.0) & 20(16.3)\end{array}$

Substance use ever, $\mathbf{n}(\%)$

$\begin{array}{ll}\text { Tobacco } & 154(38.3) \\ \text { Alcohol } & 312(77.6) \\ \text { Cannabis } & 308(76.6) \\ \begin{array}{l}\text { Any other drugs (amphetamine, co- } \\ \text { caine, opioids, sedatives, or inhalants) }\end{array} & 88(21.9)\end{array}$

$26(72.2)$

$35(28.5)$

29 (80.6)

97 (78.9)

$30(83.3)$

$100(81.3)$

$15(41.7)$

$27(22.0)$

${ }^{\mathrm{a} A M S A B}$ : assigned male sex at birth. 


\section{Discussion}

\section{Principal Findings}

The lack of data focused on identifying, recruiting, and engaging YBLMSM and YBLTW who are living with or at risk of acquiring HIV and have high rates of substance use contribute to health disparities and a public health crisis in this population.

Previous studies have described the use of RDS as an effective strategy to reach hard-to-reach populations. Some have also demonstrated challenges (eg, slow propagation) in reaching YBLMSM and YBLTW, though these studies have failed to examine different seed selection methods used in RDS [94]. The PUSH study allows us to examine assumptions about RDS seed selection methods and barriers to participating in research, which may help to inform future recruitment and sampling methods for interventions with sexual and gender minority youth.

This intervention study collects critical data on whether modification of an existing model for persons living with HIV can be used for YBLMSM and YBLTW living with HIV and those at risk for HIV. Evaluation of the PUSH study will address multiple gaps, including what components (eg, mobile app, telephone, and coach support) are needed to improve youth-based interventions to be more accessible and able to simultaneously address HIV treatment or prevention and substance use care. Although peer support is thought to be an additional strategy to improve access to care in this population [95-97], the gap in existing knowledge about the impact of coaches and/or peer-based strategies leaves prevention and treatment programs uncertain about their efficacy and effectiveness.

\section{Limitations}

There are limitations noted in this protocol. The focus population is only YBLMSM and YBLTW, limiting the generalizability of the findings. The focus groups were small and completed in 1 city, with feedback from 1 youth advisory board. We further clarified areas identified from focus groups in in-depth interviews across the cities, but this intervention may not be reflective of all the needs of YBLMSM and YBLTW. The protocol sample size estimates are based on high retention estimates.

Despite these limitations, the results of this study have the potential to significantly impact the medical and substance use services provided to YBLMSM and YBLTW in the United States by providing rigorous scientific evidence outlining approaches and strategies to improve uptake and engagement in HIV and prevention cascade. Despite accounting for disproportionate rates of HIV, most interventions in youth do not focus only on youth of color. This study focuses solely on youth of color in 3 urban cities. A major strength of the PUSH study is that it further provides information about the use of a multi-city approach to engage youth of color, along with exploring similarities and differences across locations. This work will provide data on the prevention, treatment, and sexual health trajectories of YBLMSM and YBLTW, including how to promote facilitators, address barriers to engaging in care, and end the HIV epidemic in this population.

\section{Acknowledgments}

This study was supported by the National Institutes of Health (R01DA043089) through the NIDA and the Johns Hopkins University Center for AIDS Research (P30AI094189). The authors acknowledge the contribution of the investigators and staff of PUSH Study Group at participating research sites, including the Johns Hopkins University, Baltimore, MD (F Shorrock, J Conley, and A Alvarenga); Philadelphia, PA (A Schlupp, A Lopez, and W Vickroy); and Washington, DC (R Carr, J Leslie, and B Smith). The authors also thank the Public Health Management Corporation (A Brooks, D Festinger, and G Grimaldi) for their edits and feedback to the manuscript and the Johns Hopkins University and the CHOP's Adolescent Medicine Teen Advisory Boards, who provided feedback on the study materials. The authors thank all the adolescents and young adults who participated in this project for their time and effort.

The collaborators from the PUSH study are as follows: Fionna Shorrock, James Conley, Aubrey Alvarenga, Anderson Schlupp, Alexander Lopez, William Vickroy, Rashida Carr, James Leslie, Blaine Smith, Adam Brooks, David Festinger, and Gabriella Grimaldi

\section{Conflicts of Interest}

None declared.

\section{References}

1. National HIV/AIDS Strategy: Updated to 2020 What You Need to Know. Documents \& Shareables. 2019. URL: https:/ /files.hiv.gov/s3fs-public/nhas-update-what-you-need-to-know.pdf [accessed 2019-12-28]

2. Behavioral and Clinical Characteristics of Persons with Diagnosed HIV Infection: Medical Monitoring Project, United States 2016 Cycle (June 2016-May 2017). Centers for Disease Control and Prevention. 2016. URL: https://www.cdc.gov/ hiv/pdf/library/reports/surveillance/cdc-hiv-surveillance-special-report-number-21.pdf [accessed 2020-07-28]

3. Kanny D, Jeffries WL, Chapin-Bardales J, Denning P, Cha S, Finlayson T, National HIV Behavioral Surveillance Study Group. Racial/ethnic disparities in HIV preexposure prophylaxis among men who have sex with men - 23 urban areas, 2017. MMWR Morb Mortal Wkly Rep 2019 Sep 20;68(37):801-806 [FREE Full text] [doi: 10.15585/mmwr.mm6837a2] [Medline: $\underline{31536484]}$ 
4. Diagnoses of HIV Infection in the United States and Dependent Areas, 2017. Center for Disease Control and Prevention. 2019. URL: https://www.cdc.gov/hiv/pdf/library/reports/surveillance/cdc-hiv-surveillance-report-2017-vol-29.pdf [accessed 2019-12-28]

5. McCree DH, Walker T, DiNenno E, Hoots B, Valverde E, Ocfemia MC, et al. A programmatic approach to address increasing HIV diagnoses among Hispanic/Latino MSM, 2010-2014. Prev Med 2018 Sep;114:64-71. [doi: 10.1016/j.ypmed.2018.06.007] [Medline: 29908762]

6. McNairy ML, El-Sadr WM. Antiretroviral therapy for the prevention of HIV transmission: what will it take? Clin Infect Dis 2014 Apr;58(7):1003-1011 [FREE Full text] [doi: 10.1093/cid/ciu018] [Medline: 24429438]

7. Torian LV, Wiewel EW. Continuity of HIV-related medical care, New York City, 2005-2009: do patients who initiate care stay in care? AIDS Patient Care STDS 2011 Feb;25(2):79-88. [doi: 10.1089/apc.2010.0151] [Medline: 21284498]

8. Millett GA, Peterson JL, Flores SA, Hart TA, Jeffries WL, Wilson PA, et al. Comparisons of disparities and risks of HIV infection in black and other men who have sex with men in Canada, UK, and USA: a meta-analysis. Lancet 2012 Jul 28;380(9839):341-348. [doi: 10.1016/S0140-6736(12)60899-X] [Medline: 22819656]

9. Zanoni BC, Mayer KH. The adolescent and young adult HIV cascade of care in the United States: exaggerated health disparities. AIDS Patient Care STDS 2014 Mar;28(3):128-135 [FREE Full text] [doi: 10.1089/apc.2013.0345] [Medline: 24601734]

10. Kalichman SC, Hernandez D, Finneran S, Price D, Driver R. Transgender women and HIV-related health disparities: falling off the HIV treatment cascade. Sex Health 2017 Oct;14(5):469-476. [doi: 10.1071/SH17015] [Medline: 28870282]

11. Horberg MA, Hurley LB, Klein DB, Towner WJ, Kadlecik P, Antoniskis D, et al. The HIV care cascade measured over time and by age, sex, and race in a large national integrated care system. AIDS Patient Care STDS 2015 Nov;29(11):582-590. [doi: 10.1089/apc.2015.0139] [Medline: 26505968]

12. Jenness SM, Maloney KM, Smith DK, Hoover KW, Goodreau SM, Rosenberg ES, et al. Addressing gaps in HIV preexposure prophylaxis care to reduce racial disparities in HIV incidence in the United States. Am J Epidemiol 2019 Apr 1;188(4):743-752 [FREE Full text] [doi: 10.1093/aje/kwy230] [Medline: 30312365]

13. Finlayson T, Cha S, Xia M, Trujillo L, Denson D, Prejean J, National HIV Behavioral Surveillance Study Group. Changes in HIV preexposure prophylaxis awareness and use among men who have sex with men - 20 urban areas, 2014 and 2017. MMWR Morb Mortal Wkly Rep 2019 Jul 12;68(27):597-603 [FREE Full text] [doi: 10.15585/mmwr.mm6827a1] [Medline: 31298662]

14. Pecoraro A, Royer-Malvestuto C, Rosenwasser B, Moore K, Howell A, Ma M, et al. Factors contributing to dropping out from and returning to HIV treatment in an inner city primary care HIV clinic in the United States. AIDS Care 2013;25(11):1399-1406. [doi: 10.1080/09540121.2013.772273] [Medline: 23428205]

15. Newcomb ME, Ryan DT, Greene GJ, Garofalo R, Mustanski B. Prevalence and patterns of smoking, alcohol use, and illicit drug use in young men who have sex with men. Drug Alcohol Depend 2014 Aug 1;141:65-71 [FREE Full text] [doi: 10.1016/j.drugalcdep.2014.05.005] [Medline: 24907774]

16. Newcomb ME, Hill R, Buehler K, Ryan DT, Whitton SW, Mustanski B. High burden of mental health problems, substance use, violence, and related psychosocial factors in transgender, non-binary, and gender diverse youth and young adults. Arch Sex Behav 2020 Feb;49(2):645-659. [doi: 10.1007/s10508-019-01533-9] [Medline: 31485801]

17. Garofalo R, Wolf RC, Kessel S, Palfrey SJ, DuRant RH. The association between health risk behaviors and sexual orientation among a school-based sample of adolescents. Pediatrics 1998 May;101(5):895-902. [doi: 10.1542/peds.101.5.895] [Medline: 9565422]

18. Mimiaga MJ, Closson EF, Kothary V, Mitty JA. Sexual partnerships and considerations for HIV antiretroviral pre-exposure prophylaxis utilization among high-risk substance using men who have sex with men. Arch Sex Behav 2014 Jan;43(1):99-106 [FREE Full text] [doi: 10.1007/s10508-013-0208-8] [Medline: 24243002]

19. Brown MJ, Serovich JM, Laschober TC, Kimberly JA. Age and racial disparities in substance use and self-reported viral suppression among men who have sex with men with HIV. Int J STD AIDS 2018 Oct;29(12):1174-1182 [FREE Full text] [doi: 10.1177/0956462418779663] [Medline: 29945540]

20. Oostrom L, Rosentel K, Motley D, Hill B. Discordance in objective and self-perceived HIV risk: a potential barrier to pre-exposure prophylaxis in young gay and bisexual men. J Assoc Nurses AIDS Care 2020;31(1):103-109. [doi: 10.1097/JNC.0000000000000137] [Medline: 31613824]

21. Hart TA, Noor SW, Vernon JR, Antony MM, Gardner S, O'Cleirigh C. Integrated cognitive-behavioral therapy for social anxiety and HIV/STI prevention for gay and bisexual men: a pilot intervention trial. Behav Ther 2020 May;51(3):503-517. [doi: 10.1016/j.beth.2019.09.001] [Medline: 32402264]

22. Shoptaw S. Understanding Prevention for HIV Positive Gay Men: Innovative Approaches in Addressing the AIDS Epidemic. New York, USA: Springer; 2017.

23. Kaukinen C, Fulcher C. Mapping the social demography and location of HIV services across Toronto neighbourhoods. Health Soc Care Community 2006 Jan;14(1):37-48. [doi: 10.1111/j.1365-2524.2005.00595.x] [Medline: 16324186]

24. Case C, Hawthorne TL. Served or unserved? A site suitability analysis of social services in Atlanta, Georgia using geographic information systems. Appl Geogr 2013 Mar;38:96-106. [doi: 10.1016/j.apgeog.2012.11.012] 
25. Rosentel K, VandeVusse A, Hill BJ. Racial and socioeconomic inequity in the spatial distribution of LGBTQ human services: an exploratory analysis of LGBTQ services in Chicago. Sex Res Soc Policy 2019 Feb 2;17(1):87-103. [doi: 10.1007/s13178-019-0374-0]

26. Pierce SJ, Miller RL, Morales MM, Forney J. Identifying HIV prevention service needs of African American men who have sex with men: an application of spatial analysis techniques to service planning. J Public Health Manag Pract 2007 Jan;Suppl:S72-S79. [doi: 10.1097/00124784-200701001-00012] [Medline: 17159472]

27. Ayala G, Makofane K, Santos G, Beck J, Do TD, Hebert P, et al. Access to basic HIV-related services and PrEP acceptability among men who have sex with men worldwide: barriers, facilitators, and implications for combination prevention. J Sex Transm Dis 2013;2013:953123 [FREE Full text] [doi: 10.1155/2013/953123] [Medline: 26316968]

28. Felner JK, Dudley TD, Ramirez-Valles J. 'Anywhere but here': querying spatial stigma as a social determinant of health among youth of color accessing LGBTQ services in Chicago's Boystown. Soc Sci Med 2018 Sep;213:181-189 [FREE Full text] [doi: 10.1016/j.socscimed.2018.08.001] [Medline: 30099259]

29. Calabrese SK, Earnshaw VA, Underhill K, Hansen NB, Dovidio JF. The impact of patient race on clinical decisions related to prescribing HIV pre-exposure prophylaxis (PrEP): assumptions about sexual risk compensation and implications for access. AIDS Behav 2014 Feb;18(2):226-240 [FREE Full text] [doi: 10.1007/s10461-013-0675-x] [Medline: 24366572]

30. Lacombe-Duncan A. An intersectional perspective on access to HIV-related healthcare for transgender women. Transgend Health 2016;1(1):137-141 [FREE Full text] [doi: 10.1089/trgh.2016.0018] [Medline: 29159304]

31. Flores D, McKinney R, Arscott J, Barroso J. Obtaining waivers of parental consent: a strategy endorsed by gay, bisexual, and queer adolescent males for health prevention research. Nurs Outlook 2018;66(2):138-148 [FREE Full text] [doi: 10.1016/j.outlook.2017.09.001] [Medline: 28993074]

32. Fuqua V, Chen Y, Packer T, Dowling T, Ick TO, Nguyen B, et al. Using social networks to reach Black MSM for HIV testing and linkage to care. AIDS Behav 2012 Feb;16(2):256-265. [doi: 10.1007/s10461-011-9918-x] [Medline: 21390535]

33. Ongwandee S, Lertpiriyasuwat C, Khawcharoenporn T, Chetchotisak P, Thiansukhon E, Leerattanapetch N, et al. Implementation of a test, treat, and prevent HIV program among men who have sex with men and transgender women in Thailand, 2015-2016. PLoS One 2018;13(7):e0201171 [FREE Full text] [doi: 10.1371/journal.pone.0201171] [Medline: $\underline{30044867]}$

34. Young LE, Schumm P, Alon L, Bouris A, Ferreira M, Hill B, et al. PrEP Chicago: a randomized controlled peer change agent intervention to promote the adoption of pre-exposure prophylaxis for HIV prevention among young Black men who have sex with men. Clin Trials 2018 Feb;15(1):44-52 [FREE Full text] [doi: 10.1177/1740774517730012] [Medline: $\underline{28862483}$

35. Millett GA, Ding H, Marks G, Jeffries WL, Bingham T, Lauby J, et al. Mistaken assumptions and missed opportunities: correlates of undiagnosed HIV infection among black and Latino men who have sex with men. J Acquir Immune Defic Syndr 2011 Sep 1;58(1):64-71. [doi: 10.1097/QAI.0b013e31822542ad] [Medline: 21654500]

36. Wei C, McFarland W, Colfax GN, Fuqua V, Raymond HF. Reaching black men who have sex with men: a comparison between respondent-driven sampling and time-location sampling. Sex Transm Infect 2012 Dec;88(8):622-626 [FREE Full text] [doi: 10.1136/sextrans-2012-050619] [Medline: 22750886]

37. Kan M, Garfinkel DB, Samoylova O, Gray RP, Little KM. Social network methods for HIV case-finding among people who inject drugs in Tajikistan. J Int AIDS Soc 2018 Jul;21(Suppl 5):e25139 [FREE Full text] [doi: 10.1002/jia2.25139] [Medline: $\underline{30033684]}$

38. LGBTQ Consumer Products Survey Report. Community Marketing \& Insights. 2019. URL: https://communitymarketinginc. com/documents/temp/LGBTQ-Consumer-Products-Survey-2019.pdf [accessed 2019-12-28]

39. Anderson M, Jiang J. Teens, Social Media \& Technology. Public Services Alliance: Opportunity in the Cloud. 2018. URL: http://publicservicesalliance.org/wp-content/uploads/2018/06/Teens-Social-Media-Technology-2018-PEW.pdf [accessed 2019-12-28]

40. Grov C, Breslow AS, Newcomb ME, Rosenberger JG, Bauermeister JA. Gay and bisexual men's use of the internet: research from the 1990s through 2013. J Sex Res 2014;51(4):390-409 [FREE Full text] [doi: 10.1080/00224499.2013.871626] [Medline: 24754360]

41. Rhodes SD, Vissman AT, Stowers J, Miller C, McCoy TP, Hergenrather KC, et al. A CBPR partnership increases HIV testing among men who have sex with men (MSM): outcome findings from a pilot test of the CyBER/testing internet intervention. Health Educ Behav 2011 Jun;38(3):311-320 [FREE Full text] [doi: 10.1177/1090198110379572] [Medline: 21393625]

42. Muessig KE, Pike EC, Fowler B, LeGrand S, Parsons JT, Bull SS, et al. Putting prevention in their pockets: developing mobile phone-based HIV interventions for black men who have sex with men. AIDS Patient Care STDS 2013 Apr;27(4):211-222 [FREE Full text] [doi: 10.1089/apc.2012.0404] [Medline: 23565925]

43. Hightow-Weidman LB, LeGrand S, Muessig KE, Simmons RA, Soni K, Choi SK, et al. A randomized trial of an online risk reduction intervention for young black MSM. AIDS Behav 2019 May;23(5):1166-1177 [FREE Full text] [doi: 10.1007/s10461-018-2289-9] [Medline: $\underline{30269231]}$ 
44. Easton D, Iverson E, Cribbin M, Wilson E, Weiss G, Community Intervention Trial For Youth Group. Space: the new frontier in HIV prevention for young men who have sex with men. AIDS Educ Prev 2007 Dec;19(6):465-478. [doi: 10.1521/aeap.2007.19.6.465] [Medline: 18190272 ]

45. Griffin JP. The building resiliency and vocational excellence (BRAVE) program: a violence-prevention and role model program for young, African American males. J Health Care Poor Underserved 2005 Nov; 16(4 Suppl B):78-88. [doi: 10.1353/hpu.2005.0113] [Medline: 16327109]

46. Garcia J, Parker C, Parker RG, Wilson PA, Philbin M, Hirsch JS. Psychosocial implications of homophobia and HIV stigma in social support networks: insights for high-impact HIV prevention among black men who have sex with men. Health Educ Behav 2016 Apr;43(2):217-225 [FREE Full text] [doi: 10.1177/1090198115599398] [Medline: 27037286]

47. Mugavero MJ, Amico KR, Horn T, Thompson MA. The state of engagement in HIV care in the United States: from cascade to continuum to control. Clin Infect Dis 2013 Oct;57(8):1164-1171. [doi: 10.1093/cid/cit420] [Medline: 23797289]

48. HIV Prevention Progress Report. Centers for Disease Control and Prevention. 2019. URL: https://www.cdc.gov/hiv/pdf/ policies/progressreports/cdc-hiv-preventionprogressreport.pdf [accessed 2019-12-28]

49. Creswell J, Plano CV. Choosing a mixed methods design. In: Designing and Conducting Mixed Methods Research. Second Edition. Los Angeles, USA: SAGE; 2011.

50. Creswell J. Research Design: Qualitative, Quantitative, and Mixed Methods Approaches. Second Edition. Thousand Oaks, CA: Sage Publications; 2003.

51. Holzman SB, Zenilman A, Shah M. Advancing patient-centered care in tuberculosis management: a mixed-methods appraisal of video directly observed therapy. Open Forum Infect Dis 2018 Apr;5(4):ofy046 [FREE Full text] [doi: 10.1093/ofid/ofy046] [Medline: 29732378]

52. Glaser BG. The constant comparative method of qualitative analysis. Soc Prob 1965 Apr;12(4):436-445. [doi: 10.1525/sp.1965.12.4.03a00070]

53. Strauss A, Corbin J. Basics of Qualitative Research. Newbury Park, CA: Sage Publications; 1990.

54. Arrington-Sanders R, Hailey-Fair K, Wirtz AL, Morgan A, Brooks D, Castillo M, et al. Role of structural marginalization, HIV stigma, and mistrust on HIV prevention and treatment among young Black Latinx men who have sex with men and transgender women: perspectives from youth service providers. AIDS Patient Care STDS 2020 Jan;34(1):7-15. [doi: 10.1089/apc.2019.0165] [Medline: 31944853]

55. Zucker KJ. Epidemiology of gender dysphoria and transgender identity. Sex Health 2017 Oct;14(5):404-411. [doi: 10.1071/SH17067] [Medline: 28838353]

56. PUSH. John Hopkins University. URL: https://push.nursing.jhu.edu [accessed 2020-08-06]

57. Heckathorn DD. Respondent-driven sampling: a new approach to the study of hidden populations. Soc Prob 1997 May;44(2):174-199. [doi: 10.2307/3096941]

58. Heckathorn DD, Jeffri J. Finding the beat: using respondent-driven sampling to study jazz musicians. Poetics 2001 Feb;28(4):307-329. [doi: 10.1016/s0304-422x(01)80006-1]

59. Decker MR, Marshall BD, Emerson M, Kalamar A, Covarrubias L, Astone N, et al. Respondent-driven sampling for an adolescent health study in vulnerable urban settings: a multi-country study. J Adolesc Health 2014 Dec;55(6 Suppl):S6-12 [FREE Full text] [doi: 10.1016/j.jadohealth.2014.07.021] [Medline: 25454005]

60. Wilton J, Mishra S, Tan DH. Considerations for using the HIRI-MSM screening tool to identify MSM who would benefit most from PrEP. J Acquir Immune Defic Syndr 2017 Oct 1;76(2):e58-e61. [doi: 10.1097/QAI.0000000000001472] [Medline: 28903127]

61. Smith DK, Pals SL, Herbst JH, Shinde S, Carey JW. Development of a clinical screening index predictive of incident HIV infection among men who have sex with men in the United States. J Acquir Immune Defic Syndr 2012 Aug 1;60(4):421-427. [doi: 10.1097/QAI.0b013e318256b2f6] [Medline: 22487585]

62. Mayfield W. The development of an internalized homonegativity inventory for gay men. J Homosex 2001;41(2):53-76. [doi: $10.1300 / \mathrm{J} 082 \mathrm{v} 41 \mathrm{n} 02$ 04] [Medline: 11482428 ]

63. Prado G, Pratt IA, Feaster DJ, Robinson-Batista C, Smith L, Charles M, et al. Differences in Adjustment in HIV+ African American heterosexual and homosexual women. J Gay Lesbian Med Assoc 2002 Mar;6(1):19-26 [FREE Full text] [doi: 10.1023/A:1020336731655] [Medline: 16609748]

64. Kroenke K, Spitzer RL, Williams JB, Löwe B. An ultra-brief screening scale for anxiety and depression: the PHQ-4. Psychosomatics 2009;50(6):613-621. [doi: 10.1176/appi.psy.50.6.613] [Medline: 19996233]

65. Foa EB, Johnson KM, Feeny NC, Treadwell KR. The child PTSD symptom scale: a preliminary examination of its psychometric properties. J Clin Child Psychol 2001 Sep;30(3):376-384. [doi: 10.1207/S15374424JCCP3003_9] [Medline: $\underline{11501254]}$

66. Sternthal MJ, Slopen N, Williams DR. Racial disparities in health: how much does stress really matter? Du Bois Rev 2011;8(1):95-113 [FREE Full text] [doi: 10.1017/S1742058X11000087] [Medline: 29887911]

67. Wilkerson JM, Noor SW, Galos DL, Rosser BR. Correlates of a single-item indicator versus a multi-item scale of outness about same-sex attraction. Arch Sex Behav 2016 Jul;45(5):1269-1277 [FREE Full text] [doi: 10.1007/s10508-015-0605-2] [Medline: 26292840] 
68. Dahlberg L, Toal S, Swahn M, Behrens C. Measuring Violence-Related Attitudes, Behaviors, and Influences Among Youths: A Compendium of Assessment Tools. Centers for Disease Control and Prevention. 2005. URL: https://www. cdc.gov/violenceprevention/pdf/yv compendium.pdf [accessed 2020-08-06]

69. Janda LH, Bazemore SD. The revised Mosher sex-guilt scale: its psychometric properties and a proposed ten-item version. J Sex Res 2011 Jul;48(4):392-396. [doi: 10.1080/00224499.2010.482216] [Medline: 20432133]

70. Mustanski B, Andrews R, Puckett JA. The effects of cumulative victimization on mental health among lesbian, gay, bisexual, and transgender adolescents and young adults. Am J Public Health 2016 Mar;106(3):527-533. [doi: 10.2105/AJPH.2015.302976] [Medline: 26794175]

71. Canty-Mitchell J, Zimet GD. Psychometric properties of the multidimensional scale of perceived social support in urban adolescents. Am J Community Psychol 2000 Jun;28(3):391-400. [doi: 10.1023/A:1005109522457] [Medline: 10945123]

72. Knight JR, Shrier LA, Bravender TD, Farrell M, Bilt JV, Shaffer HJ. A new brief screen for adolescent substance abuse. Arch Pediatr Adolesc Med 1999 Jun;153(6):591-596. [doi: 10.1001/archpedi.153.6.591] [Medline: 10357299]

73. Knight JR, Sherritt L, Shrier LA, Harris SK, Chang G. Validity of the CRAFFT substance abuse screening test among adolescent clinic patients. Arch Pediatr Adolesc Med 2002 Jun;156(6):607-614. [doi: 10.1001/archpedi.156.6.607] [Medline: 12038895]

74. Haley DF, Lucas J, Golin CE, Wang J, Hughes JP, Emel L, HPTN 064 Study Team. Retention strategies and factors associated with missed visits among low income women at increased risk of HIV acquisition in the US (HPTN 064). AIDS Patient Care STDS 2014 Apr;28(4):206-217 [FREE Full text] [doi: 10.1089/apc.2013.0366] [Medline: 24697160]

75. Remien RH, Stirratt MJ, Dognin J, Day E, El-Bassel N, Warne P. Moving from theory to research to practice. Implementing an effective dyadic intervention to improve antiretroviral adherence for clinic patients. J Acquir Immune Defic Syndr 2006 Dec 1;43(Suppl 1):S69-S78. [doi: 10.1097/01.qai.0000248340.20685.7d] [Medline: 17133206]

76. Robbins RN, Mellins CA, Leu C, Rowe J, Warne P, Abrams EJ, et al. Enhancing lay counselor capacity to improve patient outcomes with multimedia technology. AIDS Behav 2015 Jun;19(Suppl 2):163-176 [FREE Full text] [doi: 10.1007/s10461-014-0988-4] [Medline: 25566763]

77. Naar-King S, Suarez M. Motivational Interviewing with Adolescents and Young Adults. New York, USA: Guilford Press; 2011.

78. Outlaw AY, Naar-King S, Parsons JT, Green-Jones M, Janisse H, Secord E. Using motivational interviewing in HIV field outreach with young African American men who have sex with men: a randomized clinical trial. Am J Public Health 2010 Apr 1;100(Suppl 1):S146-S151. [doi: 10.2105/AJPH.2009.166991] [Medline: 20147689]

79. Prochaska JO, DiClemente CC. Transtheoretical therapy: toward a more integrative model of change. Psychotherapy 1982;19(3):276-288. [doi: 10.1037/h0088437]

80. Miller W, Rollnick S. Motivational Interviewing, Second Edition: Preparing People for Change. New York, USA: Guilford Press; 2002.

81. Mitchell SG, Gryczynski J, O'Grady KE, Schwartz RP. SBIRT for adolescent drug and alcohol use: current status and future directions. J Subst Abuse Treat 2013;44(5):463-472 [FREE Full text] [doi: 10.1016/j.jsat.2012.11.005] [Medline: $\underline{23352110]}$

82. Beyrer C, Remien R. HPTN 078 Enhancing Recruitment, Linkage to Care and Treatment for HIV-Infected Men Who Have Sex with Men (MSM) in the United States. The HIV Prevention Trials Network. 2015. URL: https://www.hptn.org/sites/ default/files/2016-05/HPTN\%20078\%20Protocol\%20Final\%20V1.0\%2080ct2015.pdf [accessed 2020-07-28]

83. Deci E, Ryan R. Motivation, personality, and development within embedded social contexts: an overview of self-determination theory. In: The Oxford Handbook of Human Motivation. Oxford, UK: Oxford University Press; 2012.

84. Ryan P. Integrated theory of health behavior change: background and intervention development. Clin Nurse Spec 2009;23(3):161-70; quiz 171 [FREE Full text] [doi: 10.1097/NUR.0b013e3181a42373] [Medline: 19395894]

85. WHO ASSIST Working Group. The alcohol, smoking and substance involvement screening test (ASSIST): development, reliability and feasibility. Addiction 2002 Sep;97(9):1183-1194. [doi: 10.1046/j.1360-0443.2002.00185.x] [Medline: 12199834]

86. Mitchell SG, Kelly SM, Gryczynski J, Myers CP, O'Grady KE, Kirk AS, et al. The CRAFFT cut-points and DSM-5 criteria for alcohol and other drugs: a reevaluation and reexamination. Subst Abus 2014;35(4):376-380 [FREE Full text] [doi: 10.1080/08897077.2014.936992] [Medline: 25036144]

87. Safren SA, Otto MW, Worth JL. Life-steps: applying cognitive behavioral therapy to HIV medication adherence. Cogn Behav Pract 1999 Sep;6(4):332-341. [doi: 10.1016/S1077-7229(99)80052-2]

88. Remien RH, Stirratt MJ, Dolezal C, Dognin JS, Wagner GJ, Carballo-Dieguez A, et al. Couple-focused support to improve HIV medication adherence: a randomized controlled trial. AIDS 2005 May 20;19(8):807-814. [doi: 10.1097/01.aids.0000168975.44219.45] [Medline: 15867495]

89. Wirtz AL, Poteat T, Radix A, Althoff KN, Cannon CM, Wawrzyniak AJ, American Cohort To Study HIV Acquisition Among Transgender Women (LITE). American cohort to study HIV acquisition among transgender women in high-risk areas (the lite study): protocol for a multisite prospective cohort study in the eastern and southern United States. JMIR Res Protoc 2019 Oct 3;8(10):e14704 [FREE Full text] [doi: 10.2196/14704] [Medline: 31584005]

90. Schonlau M, Liebau E. Respondent-driven sampling. Stata J 2018 Nov 19;12(1):72-93. [doi: 10.1177/1536867x1201200106] 
91. Zeger SL, Liang KY, Albert PS. Models for longitudinal data: a generalized estimating equation approach. Biometrics 1988 Dec;44(4):1049-1060. [Medline: $\underline{\text { 3233245] }}$

92. Robins JM, Rotnitzky A. Semiparametric efficiency in multivariate regression models with missing data. J Am Stat Assoc 1995 Mar;90(429):122-129. [doi: 10.1080/01621459.1995.10476494]

93. Preisser JS, Lohman KK, Rathouz PJ. Performance of weighted estimating equations for longitudinal binary data with drop-outs missing at random. Stat Med 2002 Oct 30;21(20):3035-3054. [doi: 10.1002/sim.1241] [Medline: 12369080]

94. Kuhns LM, Kwon S, Ryan DT, Garofalo R, Phillips G, Mustanski BS. Evaluation of respondent-driven sampling in a study of urban young men who have sex with men. J Urban Health 2015 Feb;92(1):151-167 [FREE Full text] [doi: 10.1007/s11524-014-9897-0] [Medline: 25128301]

95. Gonzalez JS, Penedo FJ, Antoni MH, Durán RE, McPherson-Baker S, Ironson G, et al. Social support, positive states of mind, and HIV treatment adherence in men and women living with HIV/AIDS. Health Psychol 2004 Jul;23(4):413-418. [doi: 10.1037/0278-6133.23.4.413] [Medline: 15264978]

96. Herrick AL, Stall R, Chmiel JS, Guadamuz TE, Penniman T, Shoptaw S, et al. It gets better: resolution of internalized homophobia over time and associations with positive health outcomes among MSM. AIDS Behav 2013 May;17(4):1423-1430 [FREE Full text] [doi: 10.1007/s10461-012-0392-x] [Medline: 23283578]

97. Lauby JL, Marks G, Bingham T, Liu K, Liau A, Stueve A, et al. Having supportive social relationships is associated with reduced risk of unrecognized HIV infection among black and Latino men who have sex with men. AIDS Behav 2012 Apr;16(3):508-515. [doi: 10.1007/s10461-011-0002-3] [Medline: 21805191]

\section{Abbreviations}

ART: antiretroviral therapy

CHOP: Children's Hospital of Philadelphia

CRAFFT: car, relax, alone, forget, friends, and trouble

e-coupons: electronic coupons

eRDS: electronic respondent-driven sampling

FGDs: focus group discussions

GEE: generalized estimating equations

HPTN: HIV Prevention Trials Network

KI: key informant

KIIs: key informant interviews

LGBTQ: lesbian, gay, bisexual, transgender, queer

MEI: mobile-enhanced intervention

MI: motivational interviewing

MSM: men who have sex with men

NIDA: National Institutes of Drug Abuse

OR: odds ratio

PrEP: pre-exposure prophylaxis

PUSH: Providing Unique Support for Health

RCT: randomized controlled trial

RDS: respondent-driven sampling

SBIRT: screening, brief intervention, and referral to treatment

SOC: standard of care

SUDs: substance use disorders

TW: transgender women

YBLMSM: young Black and Latinx men who have sex with men

YBLTW: young Black and Latinx transgender women 
Edited by G Eysenbach; submitted 31.12.19; peer-reviewed by J Chapin-Bardales, K Rosentel, J Stekler, S Graham; comments to author 10.03.20; revised version received 05.05.20; accepted 03.06.20; published 16.09.20

Please cite as:

Arrington-Sanders R, Hailey-Fair K, Wirtz A, Cos T, Galai N, Brooks D, Castillo M, Dowshen N, Trexler C, D’Angelo LJ, Kwait J, Beyrer C, Morgan A, Celentano D, PUSH Study

Providing Unique Support for Health Study Among Young Black and Latinx Men Who Have Sex With Men and Young Black and Latinx Transgender Women Living in 3 Urban Cities in the United States: Protocol for a Coach-Based Mobile-Enhanced Randomized Control Trial

JMIR Res Protoc 2020;9(9):e17269

URL: https://www.researchprotocols.org/2020/9/e17269

doi: $10.2196 / 17269$

PMID: $\underline{32935662}$

CRenata Arrington-Sanders, Kimberly Hailey-Fair, Andrea Wirtz, Travis Cos, Noya Galai, Durryle Brooks, Marne Castillo, Nadia Dowshen, Constance Trexler, Lawrence J D’Angelo, Jennafer Kwait, Chris Beyrer, Anthony Morgan, David Celentano, PUSH Study. Originally published in JMIR Research Protocols (http://www.researchprotocols.org), 16.09.2020. This is an open-access article distributed under the terms of the Creative Commons Attribution License (https://creativecommons.org/licenses/by/4.0/), which permits unrestricted use, distribution, and reproduction in any medium, provided the original work, first published in JMIR Research Protocols, is properly cited. The complete bibliographic information, a link to the original publication on http://www.researchprotocols.org, as well as this copyright and license information must be included. 